\title{
Incorporating environmental information in an analysis of genotype by environment interaction for seed yield in perennial ryegrass
}

\author{
F. A. VAN EEUWIJK* \& A. ELGERSMA† \\ DLO-Centre for Plant Breeding and Reproduction Research (CPRO-DLO), P.O. BOx 16, 6700 AA Wageningen, The \\ Netherlands
}

\begin{abstract}
Seed yield in perennial ryegrass was analysed for cultivar by environment interaction. Nine cultivars were evaluated in 12 trials at two locations over a 3-year period. Earlier attempts to describe the significant cultivar by environment interaction using a regression on the environmental mean or relationships with year, soil type, harvest method, or crop age, were unsuccessful. In this paper, therefore, meteorological data were introduced as explanatory variables. Three types of analysis were used. First, residuals from the cultivar by environment two-way table corrected for main effects were regressed on the explanatory variables for each cultivar separately. Secondly, the explanatory variables were used as concomitant variables for the environmental factor in a two-way analysis of variance of genotypes by environments. Finally, the matrix of residuals from additivity was subjected to a singular value decomposition, after which environmental scores were related to values of the explanatory variables using regression and a recently developed method to calculate confidence intervals for scores. All methods led to comparable conclusions about the importance of different variables in the interaction. Of equal importance were minimum temperature in the period before ear emergence, temperature sum in the period from the beginning of anthesis until peak anthesis, and mean and maximum temperature in the period from the end of anthesis until harvest. The major component of interaction was identified as a contrast between early and late cultivars. A minor component was due to cultivars that performed relatively well in the worst environment and relatively badly in the best environment. The usefulness of so-called AMMI models is discussed and compared with that of the more traditional regression on the environmental mean model.
\end{abstract}

Keywords: AMMI analysis, confidence intervals, environmental variables, factorial regression, genotype by environment interaction, perennial ryegrass.

\section{Introduction}

Perennial ryegrass is an important grass species that is propagated by seed. Seed yields are typically low. In a previous study on the seed yields of nine cultivars in 12 trials a significant interaction between cultivars and trials was found $(P<0.001$; Elgersma, 1990a). To model this interaction a regression on the environmental mean was tried initially (Yates \& Cochran,

\section{*Correspondence.}

†Present address: Department of Field Crops and Grassland Science, Agricultural University, Haarweg 333, 6709 RZ Wageningen, The Netherlands.
1938; Mandel, 1961; Finlay \& Wilkinson, 1963). Results from this model were unsatisfactory, as only 14 per cent of the interaction sum of squares could be explained, which was not significant when tested against the deviations from regressions.

The observation that crop development rates were similar within years in the various trials, but differed among years, indicated that meteorological information might be useful in the clarification of the cultivar by trial interaction. Examples of incorporating physical measurements of the environment into models for genotype by environment interaction can be found in Abou-El-Fittouh et al. (1969), Fripp (1972), Hardwick 
\& Wood (1972), Perkins (1972), Wood (1976), Denis (1980), Saeed \& Francis (1984), Kang \& Gorman (1989), and Gorman et al. (1989).

For perennial ryegrass Hampton \& Hebblethwaite (1983) showed that minimum temperature around anthesis accounted for 70 per cent of the variation in seed numbers for cultivar S.24 over a period of 10 years. For our data it was already established that the environmental factors year, soil type, harvest method, and crop age affected the levels of seed yield, thousand-grain weight, and seed number in the 12 trials (Elgersma, 1990a, 1990b). We were, however, unable to relate these factors to the cultivar by trial interaction. In this paper we will investigate whether the interaction can be explained by meteorological variables. The illustration of the methodology will be as important as the results obtained. We will introduce a new and simple method of relating environmental information to genotype by environment interaction. It uses an expression derived by Goodman \& Haberman (1990) for the confidence limits of genotypic and environmental parameters for the interaction in socalled AMMI models (Additive Main effects and Multiplicative Interaction effects models; Perkins, 1972; Gauch, 1988). The results of this method will be compared to those of more familiar methods.

\section{Materials and methods}

\section{Trials, cultivars and measurements}

Seed yield data were obtained from 12 experimental trials (Table 1) with nine perennial ryegrass cultivars sown at two experimental sites, one having sand and the other clay, in Wageningen, The Netherlands, and harvested in 1986, 1987 and 1988. Each trial con-

Table 1 Specification of trials

\begin{tabular}{lllll}
\hline Number & Soil & $\begin{array}{l}\text { Harvest } \\
\text { year }\end{array}$ & $\begin{array}{l}\text { Production } \\
\text { year }\end{array}$ & $\begin{array}{l}\text { Harvest } \\
\text { method }\end{array}$ \\
\cline { 1 - 2 } 1 & Sand & 1986 & First & 1 \\
2 & Clay & 1986 & First & 1 \\
3 & Sand & 1986 & First & 2 \\
4 & Clay & 1986 & First & 2 \\
5 & Sand & 1987 & First & 2 \\
6 & Sand & 1987 & Second & 2 \\
7 & Clay & 1987 & Second & 2 \\
8 & Sand & 1987 & Second & 2 \\
9 & Clay & 1987 & Second & 2 \\
10 & Sand & 1988 & Second & 2 \\
11 & Sand & 1988 & First & 2 \\
12 & Clay & 1988 & First & 2 \\
\hline
\end{tabular}

sisted of a randomized blocks design with four replications. Trials were distinguished from each other by soil, year, production year of the crop (crop age), and harvest method (see also Elgersma, 1990a). The cultivars chosen were all late flowering, though significant differences occurred for maturity dates. In all trials the cultivar Perma (Pe) was the earliest, followed by Semperweide (Se), Wendy (We) and Parcour $(\mathrm{Pa})$. Compas $(\mathrm{Co})$ and Trani $(\mathrm{Tr})$ were intermediate, Vigor (Vi) was rather late, and Barenza $(\mathrm{Ba})$ and Lamora $(\mathrm{La})$ were the latest. The difference between Perma and Barenza varied from 3 to 10 days in the various trials (Elgersma, 1990a, 1990b).

Dates of ear emergence, first anthesis, peak anthesis, end of anthesis, and harvest ripeness were recorded on each plot. Subsequently five developmental periods were defined: (1) 10 days preceding ear emergence; (2) ear emergence till first anthesis; (3) first anthesis till peak anthesis; (4) peak anthesis until end of anthesis; and (5) end of anthesis until harvest. Meteorological data were recorded within $6 \mathrm{~km}$ of the experimental plots (Haarweg observation station, unpublished data). During each developmental period minimum, mean and maximum temperature, rainfall, relative humidity and wind velocity were calculated for each plot (the choice of these variables was based on information in Hampton \& Hebblethwaite, 1983). Environmental characterization of each site was derived from these data by averaging over all plots at a particular site within a particular year. Ranges of the meteorological variables over the trials are given in Table 2 for each developmental period. As can be deduced from Table 1 the following trials had identical environmental characterizations: 1 and 3;2 and 4; 5, 6 and 8; 7 and 9; 10 and 11 ; whereas 12 was the only trial with a unique characterization. Additional variables included temperature sum (defined as the length of a developmental stage multiplied by the average temperature for that stage) and period length.

\section{Statistical analyses}

All analyses had as a starting point the matrix of interaction residuals, i.e. the cultivar by trial table corrected for main effects. First, interaction residuals were regressed for each cultivar separately on the weather variables including developmental period length. Orthogonalized squares of the weather variables were included as well. Secondly, a simultaneous regression of the interaction residuals on the weather variables was performed by introducing these variables as concomitant variables for the environmental factor in the two-way analysis of variance for the cultivar by trials table (Snedecor \& Cochran, 1980, Chpt. 16). The 
Table 2 Ranges of environmental variables during five developmental stages. For definition of the periods see text

\begin{tabular}{|c|c|c|c|c|c|c|c|c|c|c|}
\hline & \multicolumn{10}{|l|}{ Period } \\
\hline & \multicolumn{2}{|l|}{1} & \multicolumn{2}{|l|}{2} & \multicolumn{2}{|l|}{3} & \multicolumn{2}{|l|}{4} & \multicolumn{2}{|l|}{5} \\
\hline & $\min$. & $\max$. & $\min$. & $\max$. & $\min$. & $\max$ & $\min$. & $\max$. & $\min$. & $\max$ \\
\hline $\begin{array}{l}\text { Length period } \\
\text { (days) }\end{array}$ & 10 & 10 & 11 & 23 & 2 & 9 & 7 & 16 & 14 & 25 \\
\hline Mean temp. $\left({ }^{\circ} \mathrm{C}\right)$ & 12.3 & 15.2 & 13.4 & 19.3 & 15.1 & 22.7 & 14.9 & 18.7 & 14.6 & 17.7 \\
\hline Min. temp. $\left({ }^{\circ} \mathrm{C}\right)$ & 7.7 & 9.4 & 9.3 & 12.3 & 9.2 & 14.2 & 10.7 & 13.0 & 10.9 & 12.6 \\
\hline $\operatorname{Max}$. temp. $\left({ }^{\circ} \mathrm{C}\right)$ & 16.5 & 19.6 & 17.3 & 24.7 & 19.2 & 32.1 & 19.0 & 23.7 & 18.3 & 27.6 \\
\hline $\begin{array}{l}\text { Temp. sum } \\
\left({ }^{\circ} \mathrm{C} \text { days }\right)\end{array}$ & 123.0 & 152.0 & 174.2 & 324.3 & 45.4 & 154.7 & 104.3 & 280.3 & 247.8 & 402.5 \\
\hline Rel. hum. $(\%)$ & 74.3 & 82.3 & 66.1 & 89.1 & 56.7 & 93.5 & 66.1 & 85.4 & 78.7 & 86.6 \\
\hline Rainfall (mm) & 11.9 & 57.8 & 3.9 & 37.0 & 0.0 & 5.5 & 6.9 & 50.6 & 32.3 & 105.6 \\
\hline $\begin{array}{l}\text { Wind velocity } \\
\left(\mathrm{km} \mathrm{h}^{-1}\right)\end{array}$ & 2.5 & 3.4 & 2.3 & 3.0 & 1.3 & 2.4 & 1.9 & 2.6 & 2.4 & 3.1 \\
\hline
\end{tabular}

interaction is partitioned into a part due to regression and a part due to deviations from regression. The method was probably introduced in plant breeding by Abou-El-Fittouh et al. (1969) and has been refined and extended by Denis $(1980,1988)$ under the name of factorial regression. Both these regression methods directly relate environmental information to interaction residuals.

Alternatively, one could try to first separate out pattern from noise in the interaction residuals by means of a singular value decomposition and subsequently relate the environmental scores thus obtained to measured environmental variables. Effectively, an additive main effects and multiplicative interaction effects (AMMI) model is used (Perkins, 1972; Gauch, 1988; Zobel et al., 1988), which has the form

$Y_{i j k}=\mu+G_{i}+E_{j}+\sum_{n=1}^{N} \lambda_{n} a_{n i} b_{n j}+I_{i j}+\varepsilon_{i j k}$.

$Y_{i j k}$ is the yield for the $k$-th replication of the $i$-thp cultivar in the $j$-th trial, $\mu$ the general mean, $G_{i}$ and $E_{j}$ are the cultivar and trial effect, respectively, $\lambda_{n}$ is the $n$-th singular value from the singular value decomposition (Gabriel, 1978) of the matrix of interaction residuals, $a_{n i}$ and $b_{n j}$ are the corresponding cultivar and trial scores, $N$ is the number of multiplicative terms (axes) needed for an adequate description of the interaction, $I_{i j}$ is a residual arising from the two-way table after correction for the main effects and the extraction of the multiplicative interaction effects, and $\varepsilon_{i j k}$ represents a normally distributed intra-block error.

Estimated environmental scores were regressed on the environmental variables (the same procedure can be used to relate cultivar scores to explanatory variables). As measurements for the environmental variables tended to cluster in two groups the approach by regression was questionable, because no real check on the linearity of the relation was possible. Therefore another method was used, which does not rely on the assumption of linearity and is based on the calculation of confidence intervals for cultivar and trial scores. The general expression for an interval for a multiplicative parameter (score), $\zeta$, in an AMMI model was derived by Goodman \& Haberman $(1990)$ as $[\hat{\zeta}-\operatorname{Tsq}(\hat{\zeta})$, $\hat{\zeta}+\operatorname{Tsq}(\hat{\zeta})]$, in which T denotes the upper $\alpha / 2$ point for a $t$-distribution, $\mathrm{s}$ is the square root of the variance estimate, and $q(\hat{\zeta})$ is a function of the observations. (Those in favour of multiple comparison procedures can replace the $t$-distribution with their preferred distribution.) For the multiplicative parameter for the $i$ th row (cultivar) corresponding to the $m$-th singular value, $a_{m i}, q(\hat{\zeta})$ is the square root of

$$
\begin{aligned}
& {\left[\left(1-1 / I-\sum_{n=1}^{N} \hat{a}_{n i}^{2}\right) / \hat{\lambda}_{m}^{2}\right]} \\
& +\sum_{n \neq m, n \leq N}\left[\left(\hat{\lambda}_{m}^{2}+\hat{\lambda}_{n}^{2}\right) /\left(\hat{\lambda}_{m}^{2}-\hat{\lambda}_{n}^{2}\right)^{2}\right] \hat{a}_{n i}^{2},
\end{aligned}
$$

where $I$ is the number of rows of the two-way table, the number of cultivars. For the column parameters, $b_{m j}$, the same formula is valid with $I$ replaced by $J$, the number of colomns (trials), and the $a_{m i}$ s replaced by the $b_{m j}$ s.

Before testing a hypothesis on the relation between the observed values of an environmental variable and the environmental scores for a particular axis, the values of the environmental variable must be scaled in 
the same way as the environmental scores, e.g. with mean zero and squared length unity. Signs of observed values and scores must be aligned as much as possible, at least for the largest values. Testing involves comparing observed values with the confidence intervals for environmental scores.

\section{Results and discussion}

\section{Two-way data table and ANOVA}

Table 3 shows the cultivar by trial table of means in which each entry is a mean over four blocks. The corresponding ANOVA is given in Table 4. The sum of squares for cultivar $\times$ trial interaction looks small in comparison to the total sum of squares, but is substantial in comparison to the sum of squares for cultivars. The mean square is highly significant when tested against the mean intra-block error $(P<0.001)$. The interaction was not due to non-normality: the estimated value for the Box-Cox parameter, $\lambda$ (see Atkinson, 1985), was close to 1 . Nor could outliers be the source of the interaction as evidenced by a nonsignificant maximum normed residual of 0.2538 (Stefansky, 1972).

\section{Regressing interaction residuals on environmental variables for each cultivar separately}

Table 5 shows the results of the regressions of interaction residuals on weather variables for each cultivar. First, linear terms were tried. Because there were only six independent values for each explanatory variable, correlations had to exceed $(+/-) 0.811$ (4 d.f.) to achieve significance at $\alpha=0.05$. This value was surpassed only in Parcour for mean temp. 5, max. temp. 5, and min. temp. 1. The two highest correlated variables per cultivar are given, together with the correlations with four variables which were selected using the factorial regression and the singular value decomposition (see below). For the more unstable cultivars (those responsible for more than 10 per cent of the interaction) min. temp. 1 was most frequently found among the highest correlated variables, followed by temp. sum 3 and mean temp. 5 .

\section{Factorial regression}

The first attempt to explain the interaction included only linear terms. The best were min. temp. 1, mean temp. 5, max. temp. 5 and temp. sum 3 (see Table 6). The regression mean squares were tested over the mean intra-block error of the original experiments. Subsequently, the contributions of a second linear term and quadratic terms were investigated. The best significant second terms are also given in Table 6. It is obvious that the factorial regression represents something of an average over the individual regressions from the previous section. The best explanatory variable in the factorial regression was min. temp. 1 .

\section{AMMI analysis}

Singular value decomposition of the matrix of interaction residuals resulted in a decomposition consisting

Table 4 Two-way analysis of variance results. Error is the mean intra-block error over the 12 trials

\begin{tabular}{lrrr}
\hline Source & \multicolumn{1}{c}{ Df } & \multicolumn{1}{c}{ SS } & \multicolumn{1}{c}{ MS } \\
\hline Cultivars & 8 & $1,769,903$ & 221,238 \\
Trials & 11 & $20,643,894$ & $1,876,718$ \\
$\mathrm{C} \times \mathrm{T}$ & 88 & $1,055,090$ & 11,990 \\
Error & 288 & & 5,781 \\
\hline
\end{tabular}

Table 3 Mean seed yields plus marginal means in $\mathrm{kg} \mathrm{ha}^{-1}$. For abbreviations and codes see Materials and methods and Table 1

\begin{tabular}{|c|c|c|c|c|c|c|c|c|c|c|c|c|c|}
\hline & 1 & 2 & 3 & 4 & 5 & 6 & 7 & 8 & 9 & 10 & 11 & 12 & \\
\hline $\mathrm{Se}$ & 1030 & 1844 & 1231 & 2059 & 1476 & 951 & 1250 & 956 & 1538 & 459 & 825 & 860 & 1207 \\
\hline We & 1194 & 1865 & 1431 & 2242 & 1410 & 937 & 1342 & 1079 & 1722 & 455 & 782 & 904 & 1280 \\
\hline $\mathrm{Co}$ & 992 & 1838 & 1406 & 2096 & 1217 & 813 & 1137 & 804 & 1556 & 502 & 595 & 635 & 1133 \\
\hline $\mathrm{La}$ & 1073 & 1496 & 1151 & 1558 & 927 & 539 & 921 & 555 & 1186 & 387 & 377 & 581 & 896 \\
\hline $\mathrm{Pe}$ & 829 & 1691 & 1317 & 2084 & 1284 & 805 & 1353 & 1027 & 1677 & 403 & 771 & 901 & 1178 \\
\hline $\mathrm{Ba}$ & 1102 & 1604 & 1210 & 2113 & 1011 & 567 & 1060 & 587 & 1147 & 383 & 498 & 756 & 1003 \\
\hline $\mathrm{Pa}$ & 965 & 1609 & 1221 & 1899 & 1258 & 908 & 1533 & 1066 & 1599 & 561 & 781 & 797 & 1183 \\
\hline $\operatorname{Tr}$ & 1284 & 1868 & 1580 & 2293 & 1425 & 917 & 1404 & 1111 & 1693 & 666 & 829 & 1066 & 1345 \\
\hline \multirow[t]{2}{*}{$\mathrm{Vi}$} & 1199 & 1897 & 1390 & 2138 & 1340 & 847 & 1217 & 855 & 1270 & 575 & 636 & 910 & 1189 \\
\hline & 1074 & 1746 & 1326 & 2054 & 1261 & 809 & 1246 & 893 & 1488 & 488 & 677 & 823 & 1157 \\
\hline
\end{tabular}


Table 5 Cultivar, percentage of total interaction sum of squares due to cultivar, first and second highest correlated variable to interaction residuals of a cultivar, correlations of interaction residuals with min. temp. 1, temp. sum 3, mean temp. 5 , and max. temp. 5

\begin{tabular}{|c|c|c|c|c|c|c|}
\hline \multirow[b]{2}{*}{$\begin{array}{l}\text { Cultivar } \\
\% \text { SS int. }\end{array}$} & \multirow[b]{2}{*}{$\begin{array}{l}\text { First and second } \\
\text { highest corr. } \\
\text { variable }\end{array}$} & \multirow[b]{2}{*}{$r$} & \multicolumn{4}{|l|}{$r$} \\
\hline & & & $\begin{array}{l}\min . \\
\text { temp. } \\
1\end{array}$ & $\begin{array}{l}\text { temp. } \\
\text { sum } \\
3\end{array}$ & $\begin{array}{l}\text { mean } \\
\text { temp. } \\
5\end{array}$ & $\begin{array}{l}\max . \\
\text { temp. } \\
5\end{array}$ \\
\hline $\begin{array}{l}\text { Semperweide } \\
8 \%\end{array}$ & $\begin{array}{l}\text { Rel. hum. } 5 \\
\text { Min. temp. } 3\end{array}$ & $\begin{array}{r}0.74 \\
-0.69\end{array}$ & 0.44 & -0.50 & -0.31 & -0.36 \\
\hline Wendy & Max. temp. 4 & 0.70 & 0.19 & -0.48 & -0.07 & -0.00 \\
\hline $5 \%$ & Mean temp. 4 & 0.69 & & & & \\
\hline $\begin{array}{c}\text { Compas } \\
8 \%\end{array}$ & $\begin{array}{l}\text { Rainfall } 3 \\
\text { Length per. } 5\end{array}$ & $\begin{array}{l}-0.60 \\
-0.54\end{array}$ & -0.35 & 0.12 & 0.35 & 0.42 \\
\hline $\begin{array}{c}\text { Lamora } \\
17 \%\end{array}$ & $\begin{array}{l}\text { Length per. } 4 \\
\text { Temp. sum } 4\end{array}$ & $\begin{array}{l}-0.71 \\
-0.69\end{array}$ & -0.32 & 0.49 & 0.14 & 0.16 \\
\hline $\begin{array}{l}\text { Perma } \\
14 \%\end{array}$ & $\begin{array}{l}\text { Min. temp. } 1 \\
\text { Temp. sum } 3\end{array}$ & $\begin{array}{r}0.69 \\
-0.61\end{array}$ & 0.69 & -0.61 & -0.60 & -0.63 \\
\hline $\begin{array}{c}\text { Barenza } \\
16 \%\end{array}$ & $\begin{array}{l}\text { Temp. sum } 3 \\
\text { Min. temp. } 1\end{array}$ & $\begin{array}{r}0.78 \\
-0.77\end{array}$ & -0.77 & 0.78 & 0.75 & 0.72 \\
\hline $\begin{array}{c}\text { Parcour } \\
20 \%\end{array}$ & $\begin{array}{l}\text { Mean temp. } 5 \\
\text { Min. temp. } 1\end{array}$ & $\begin{array}{r}-0.91 \\
0.86\end{array}$ & 0.86 & -0.68 & -0.91 & -0.89 \\
\hline $\begin{array}{r}\text { Trani } \\
2 \%\end{array}$ & $\begin{array}{l}\text { Rel. hum. } 5 \\
\text { Min. temp. } 3\end{array}$ & $\begin{array}{r}-0.45 \\
0.35\end{array}$ & -0.29 & 0.32 & 0.25 & 0.25 \\
\hline $\begin{array}{l}\text { Vigor } \\
11 \%\end{array}$ & $\begin{array}{l}\text { Mean temp. } 5 \\
\text { Min. temp. } 1\end{array}$ & $\begin{array}{r}0.74 \\
-0.69\end{array}$ & -0.69 & 0.57 & 0.74 & 0.69 \\
\hline
\end{tabular}

Table 6 Results of factorial regressions; best explaining single variables, best explaining pairs given best explaining singles, and some selected combinations

\begin{tabular}{ll}
\hline Variable(s) & $\%$ SS int. explained \\
\hline Min. temp. 1 & 40 \\
Min. temp. 1 + length per. 4 & 52 \\
Min. temp. 1 + min. temp. 2 & 50 \\
Mean temp. 5 & 38 \\
Mean temp. 5 + length per. 4 & 53 \\
Max. temp. 5 & 38 \\
Max. temp. 5 + length per. 4 & 53 \\
Temp. sum 3 & 35 \\
Temp. sum 3 + mean temp. 5 & 50 \\
Temp. sum 3 + temp. sum 4 & 48 \\
Length per. 3 + length ${ }^{2}$ per. 3 & 46 \\
\hline
\end{tabular}

of eight terms explaining respectively $51.1,19.4,10.8$, $10.1,4.5,2.4,1.4$ and 0.3 per cent of the interaction sum of squares. Mean squares were derived from the Eigenvalues by dividing the Eigenvalues by an approximation of the appropriate number of degrees of freedom; I $+J-1-2 n$ (Gollob, 1968; see section Statistical analyses for the meanings of symbols). When tested against the mean intra-block error only the first two Eigenvalues were significant. Calculating an estimate for the error from the non-significant Eigenvalues gave 5,764 , remarkably close to the intra block estimate of 5,781 .

An interaction that can be described by two multiplicative components can be represented concisely in a biplot (Fig. 1). Cultivars are represented by lines, trials by points. Both the end-points of the lines for the cultivars and the points for the environments must be interpreted as the end-points of vectors starting at the origin. The length of a cultivar line roughly reflects the amount of interaction for that cultivar; thus according to Fig. 1 most interaction is due to Parcour, Lamora, Barenza and Perma (for confirmation see Table 5). The (cosine of the) angle between cultivar lines corresponds to the correlation between the interraction residuals. Hence, Vigor and Barenza are quite alike, Barenza and Perma are strongly negatively correlated and Parcour and Lamora are very dissimilar with a correlation close to zero. Scaling is such that distance between cultivars is indicative of the amount of interaction between them (Kempton, 1984); e.g. between Parcour and Barenza much interaction is present. An interaction residual for a particular combination of cultivar and trial can be recovered by calculating the inner product between their respective vectors. This is equivalent to the length 


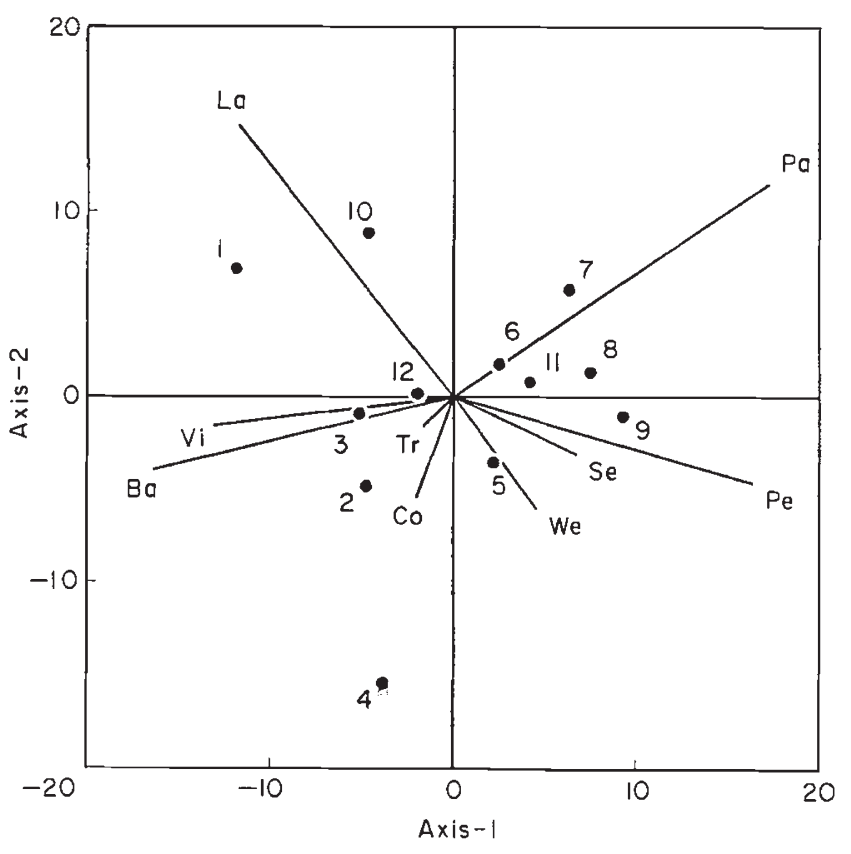

Fig. 1 Biplot constructed from cultivar (- $)$ and trial $(\bullet)$ scores on the first two axes of the AMMI analysis. For abbreviations and codes see Materials and methods and Table 1.

of the projection of either vectors onto the other multiplied by the length of the vector on which projection takes place. The sign of this product is positive if the angle between the vectors is acute, and negative for obtuse angles. Parcour can be seen to have high positive interaction residuals in trials 7,8 , and 9 , which are of equal value, and a high negative residual in trial 4 ; Perma also has high residuals for 7,8 , and 9 , but increasing in magnitude in this order; Lamora has high positive residuals in 1 and 10 , and a high negative residual in 4 .

\section{AMMI analysis first axis}

Figure 1 shows that the first axis forms a contrast between, on the left side, the late cultivars Lamora, Vigor, and Barenza, and, on the right side, the early cultivars Parcour and Perma. Environmental scores were regressed on the weather variables. Four regressions were found to be significant (Table 7 and Fig. 2). Addition of other linear or quadratic terms did not lead to significant increases in explanation. The selected variables were the same as those found by factorial regression. The separation of pattern and noise by means of a singular value decomposition with subsequent interpretation of scores through regression on environmental variables leads to the same conclusion as direct regression of interaction residuals on explana-
Table 7 Weather variables with strongest correlations to environmental scores of AMMI-axis 1,2, and environmental main effects, plus their mutual correlations

\begin{tabular}{|c|c|c|c|c|c|}
\hline & Variable & $r$ & \multicolumn{3}{|c|}{ Mutual correlations } \\
\hline $\begin{array}{l}\text { AMMI- } \\
\text { axis } \\
1\end{array}$ & $\begin{array}{ll}1 & \text { min. temp. } 1 \\
2 & \text { temp. sum } 3 \\
3 & \text { mean temp. } 5 \\
4 & \text { max. temp. } 5\end{array}$ & $\begin{array}{r}0.87 \\
-0.82 \\
-0.81 \\
-0.81\end{array}$ & $\begin{array}{l}-0.87 \\
-0.96 \\
-0.96 \\
1\end{array}$ & $\begin{array}{l}0.72 \\
0.76 \\
2\end{array}$ & $\begin{array}{l}0.99 \\
3\end{array}$ \\
\hline $\begin{array}{l}\text { AMMl- } \\
\text { axis } \\
2\end{array}$ & $\begin{array}{l}1 \text { length per. } 5 \\
2 \text { min. temp. } 2 \\
3 \text { temp. sum } 5 \\
4 \text { length per. } 4\end{array}$ & $\begin{array}{r}0.66 \\
-0.63 \\
0.61 \\
-0.58\end{array}$ & $\begin{array}{r}-0.91 \\
0.95 \\
-0.65 \\
1\end{array}$ & $\begin{array}{c}-0.76 \\
0.39 \\
2\end{array}$ & $\begin{array}{l}-0.82 \\
3\end{array}$ \\
\hline $\begin{array}{l}\text { Env. } \\
\text { main } \\
\text { effect }\end{array}$ & $\begin{array}{ll}1 & \text { length per. } 5 \\
2 & \text { temp. sum } 5 \\
3 & \text { rel. hum. } 2 \\
4 & \text { min. temp. } 2\end{array}$ & $\begin{array}{l}-0.79 \\
-0.78 \\
-0.77 \\
-0.77\end{array}$ & $\begin{array}{r}0.95 \\
0.84 \\
-0.91 \\
1\end{array}$ & $\begin{aligned} & 0.72 \\
- & 0.76 \\
& 2\end{aligned}$ & $\begin{array}{l}-0.91 \\
3\end{array}$ \\
\hline
\end{tabular}

tory variables. This agreement of methods may serve to support the claim that the most important environmental variables are included in the set of selected variables with great certainty. However, collinearity makes it difficult to decide which variables have a primary causal effect and which have an associated effect. Cultivar reactions to the environmental circumstances represented by axis 1 could just as well be reflections of a reaction to minimum temperature in the 1 st period as to temperature sum in the 3rd period, or mean or maximum temperature in the 5 th period. An answer can only be obtained by additional experimentation.

Another problem was the clumping of the data points for certain variables such as temp: sum 3 and max. temp. 5 (Fig. 2). For temp. sum 3 the data were more or less divided into two clusters, thus precluding a check on linearity, and making the regression a contrast between the environments of 1987 on the one hand, and 1986 and 1988 on the other hand.

To avoid the formulation of an explicit relationship between environmental scores and measurements, appopriately scaled variable values were compared with confidence intervals for scores (interval matching, Fig. 3). For min. temp. 1 only the observed value of trial 11 was found just outside the confidence interval for the score. For temp. sum 3 trials 1 and 5 were just outside, and 11 was clearly outside the interval. For mean and max. temp. 5 trials $1,2,8$, and 10 were outside the intervals. The agreement between scores and observed values for the different variables as assessed by interval 

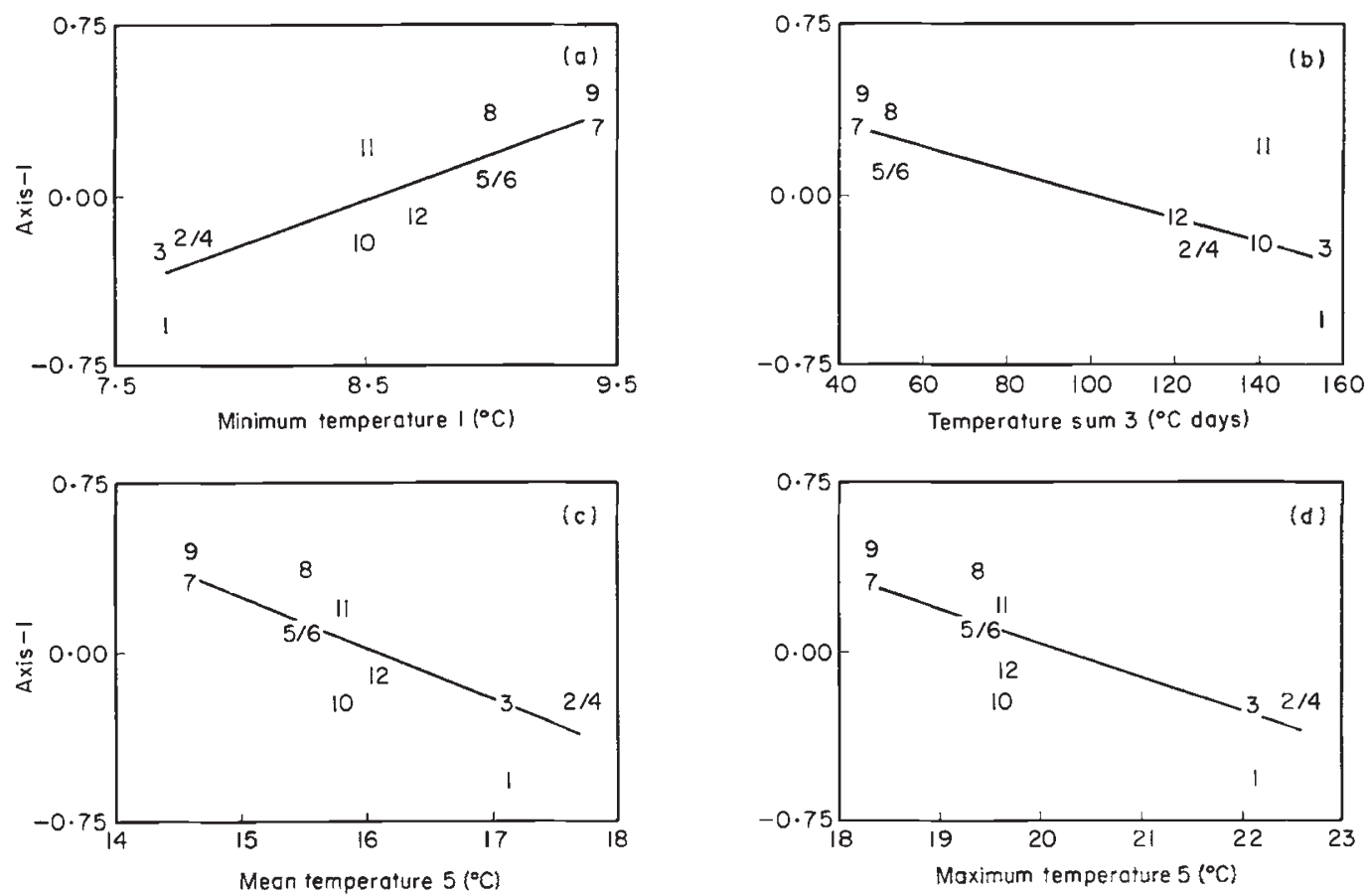

Fig. 2 Fitted $(-)$ and observed (1 ..12) values for the regressions of axis 1 environmental scores on: (a) min. temp. 1; (b) temp. sum. 3; (c) mean temp. 5; (d) max. temp. 5. For codes see Table 1.
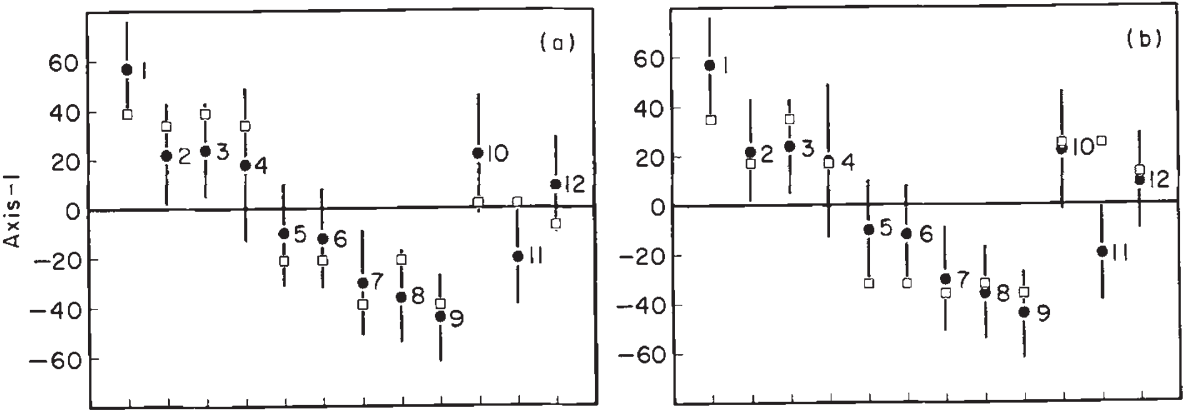

Fig. 3 Trial scores $(\bullet)$ on AMMI axis 1 with 95 per cent confidence bounds $(-)$, and scaled values ( $\square$ ) for the environmental variables: (a) min. temp. 1; (b) temp. sum. 3; (c) mean temp. 5; (d) max. temp. 5. For codes see Table 1.
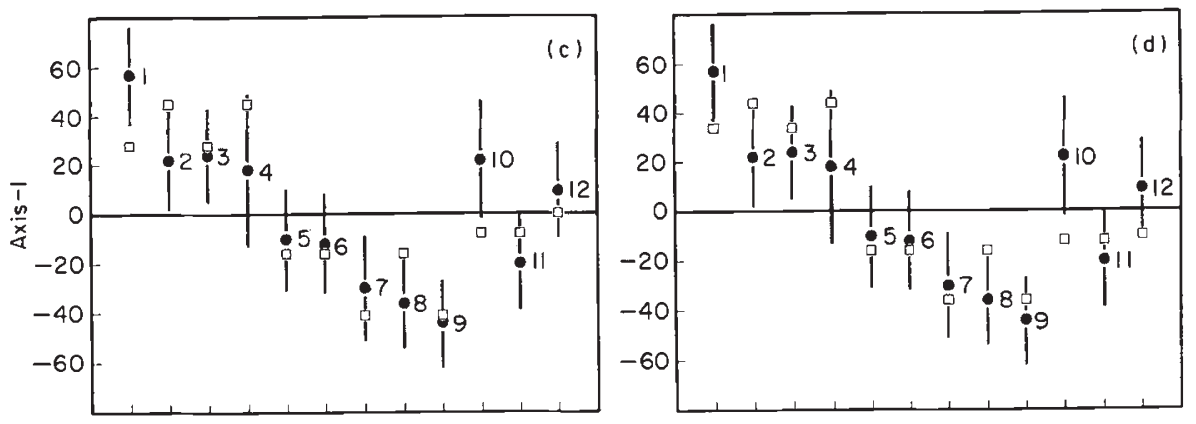

matching was thus comparable with that found by regression.

Interval matching was also used to test the hypothesis that axis 1 cultivar scores represent a contrast between early and late cultivars (Fig. 4a). The contrast involves the early cultivars Perma and Parcour with score $-3 / \sqrt{ }\left[\left(2 *-3^{2}\right)+\left(3 * 2^{2}\right)\right]$ on the one hand and the late cultivars Lamora, Vigor and Barenza with score $2 / \sqrt{ }\left[\left(2 *-3^{2}\right)+\left(3 * 2^{2}\right)\right]$ on the other hand. The other cultivars had a zero score. The denominator here is a normalizing factor which gives the vector of scores a squared length of unity. In Fig. 4a none of the contrast 

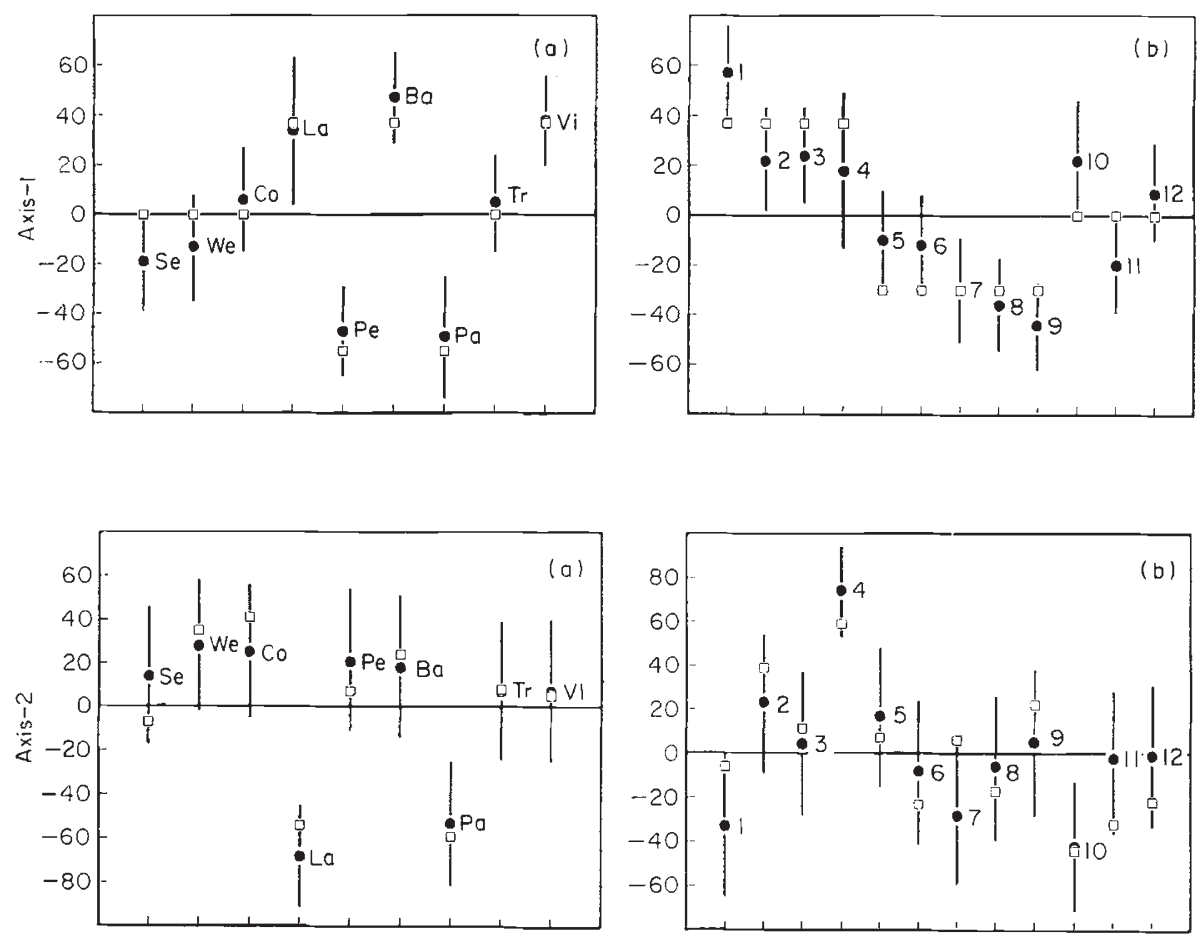

Fig. 4 (a) Cultivar scores $(\bullet)$ on AMMI axis 1 with 95 per cent confidence bounds ( $\longrightarrow$ ), and scores ( $\square$ ) for the contrast of cultivars Perma and Parcour versus Lamora, Barenza, and Vigor. For abbreviations see Materials and methods. (b) Trial scores ( ) on AMMI axis 1 with 95 per cent confidence bounds ( $\longrightarrow$ ), and scores ( $\square$ ) for the contrast between the trials of 1986 vs. those of 1987 . For codes see Table 1.

Fig. 5 (a) Cultivar scores ( $)$ on AMMI axis 2 with 95 per cent confidence bounds (-), and scaled values ( $\square$ ) for the regression on the environmental mean stabilities. For abbreviations see Materials and methods. (b) Trial scores on AMMI axis $2(\bullet)$ with 95 per cent confidence bounds $(-)$, and scaled values $(\square)$ for trial main effects. For codes see Table 1. values fall outside the confidence limits, so that axis 1 could represent a contrast between early and late cultivars.

For the environmental scores the contrasts between sand and clay, 1986-1987, 1986-1988, 1987-1988, and first- and second-year crop were investigated. None of these gave promising results except the contrast 1986-1987. This contrast was reconcilable with the axis 1 trial scores (Fig. 4b). Not surprisingly this contrast was easily discernible in the values of min. temp. 1, lower in 1986 than in 1987, and the values of temp. sum 3, mean temp. 5, and max. temp. 5, higher in 1986 than in 1987.

\section{AMMI analysis second axis}

Figure 1 shows that the second axis is dominated by the cultivars Lamora and Parcour, which had relatively low yields in the highest yielding trial, 4 , and relatively high yields in the lowest yielding trial, 10 (Table 3). Axis 2 scores for Lamora and Parcour combined with the scores for trials 4 and 10 account for 54 per cent of the sum of squares for this axis, or 10 per cent of the total interaction sum of squares. Lamora and Parcour seem to respond less to changes in the environmental factors than the other cultivars. Cultivar scores for axis 2 were correlated with the coefficients for the regressions of individual cultivar means on the average of all cultivars, $r=-0.94$. Environmental scores were corre- lated with environmental main effects, $r=-0.78$. Axis 2 thus seems to represent a regression on the environmental mean (Yates \& Cochran, 1938; Finlay \& Wilkinson, 1963). The percentage of the interaction sum of squares explained by this axis, 19 per cent was also close to that for the regression on the environmental mean, 14 per cent. Interval matching of cultivar and trial scores (Fig. 5) further subscribed to this view. In Fig. 5a zero values indicate average stability and negative values belong to the more stable cultivars, Lamora and Parcour.

The results of regressions of environmental scores on the weather variables are given in Table 7. Even the best explanatory linear term, length per. 5 , could not be shown to be significantly related to the scores. A second linear, or a quadratic term did not add anything. Regressions of the environmental main effect on the weather variables also showed that axis 2 scores and environmental main effects were very similar (Table 7).

If axis 2 trial scores are indeed reflections of an underlying environmental variable it becomes difficult to explain why Lamora and Parcour respond very clearly to the environmental circumstances in trials 4 and 10 , but almost not at all to the very similar circumstances in $2(=4)$, and $11(=10)$ (Fig. 1). Besides, it is hard to maintain that axis 2 is best interpreted in terms of stabilities, because as Fig. 5a reveals, Lamora and Parcour are the only cultivars without an average stability, while trials 4 and 10 are the only ones with 
scores deviating clearly from 0 . Probably axis 2 is better interpreted as modelling a multiple outlier for which no explanation in environmental terms is available.

\section{Regression on the environmental mean versus AMMI}

The first application of the method of regression onto the environmental mean to genotype by environment problems in grasses was probably that of Breese (1969) in his study of forage yield in cocksfoot. The method elicited enthusiasm as it seemed to provide an easily interpreted solution. Fifty-two per cent of the interaction was explained, but as Knight (1970) remarked with respect to the same data, genotype by environment interaction will remain intractable unless combinations of environmental factors are taken into consideration. Regressing individual responses on the mean of all genotypes is valuable, but only for broad studies of a collection of varieties.

Successful applications of the technique to forage yield in perennial ryegrass can be found in Troughton (1970), Samuel et al. (1970) and Hill \& Samuel (1971). The percentages of explained interaction in these papers vary from 31 to 55 . The method did not always accomplish such an adequate description of the genotype by environment interaction in grasses, as can be seen in a study of Nguyen et al. (1980) on tall fescue synthetics. In this case only 19 per cent of the interaction for the variable total herbage yield was described by heterogeneity of regression lines. In Gray (1982) total growth can be calculated at 15 per cent in an experiment with cocksfoot. Even worse is the figure for annual yield in smooth bromegrass (Tan et al., 1979) which is 12 per cent. For forage yield in reed canary grass Barker et al. (1981) concluded that stability parameters, like regression coefficients, were not consistent, and that mean yield per se appeared to be the most reliable measure to evaluate forage yield performance.

Two frequently expressed criticisms towards the regression on the environmental mean are that the amount of interaction explained is low, and that the regressions are determined by only a few points (Westcott, 1986). Both criticisms apply to the regression solution to our genotype by environment problem. It is evident that the AMMI model possesses greater versatility in modelling interaction than the regression on the mean model, because it allows modelling in more than one dimension. Therefore, the AMMI solution to a genotype by environment problem is less prone to lead to a low percentage of explained interaction. As to the percentage of explained interaction, the AMMI model outperformed the regression on the mean model for our data because it identified a major component of interaction undetected by the regression on the mean, while it simultaneously contained the regression on the mean on another axis. Regression on the environmental mean becomes part of the AMMI solution if environmental scores mimic the environmental main effect. Perkins (1972) and Freeman \& Dowker (1973) also identified an AMMI axis, the first in their cases, to be equivalent to a regression on the environmental mean.

When the majority of the interaction has a structure which deviates from the structure embodied in a regression on the environmental mean, the classical regression test on interaction, i.e. heterogeneity of slopes against deviations from regression, will often fail to detect any interaction at all. In that case the deviations from regression will provide an inappropriate measure for testing the heterogeneity of slopes. All interaction structure has to be removed from a genotype by environment table before a reasonable estimate for the error can be extracted. For our data, the estimate for the error taken from the cultivar by trial table after removing the first two multiplicative terms was almost equal to the intra block estimate. This strongly supported the conclusion that the two extracted AMMI axes represented structure, with the second axis being equivalent to regression on the mean, thereby proving the classical test on heterogeneity of slopes to be incorrect for our data.

\section{Interval matching and power}

It can be remarked that the way in which hypothesis testing proceeds with the interval matching possesses an inverse character. As the intervals become larger hypotheses become more difficult to refute. We do not think this forms a major problem as long as two conditions are fulfilled. In the expression for the confidence intervals it can be seen that the sizes of the intervals for the parameters of a particular axis are dependent on the estimate for the error, and the estimates for the scores and eigenvalues of other axes. A reliable estimate for the error, together with retainment of the appropriate number of axes, will safeguard the utility of the interval matching method. Reliability of the error estimate may be checked by comparison of the coefficient of variation for the experiment with published data or known standards. The coefficient of variation for our data was 13.1 per cent on a per plot basis. This seems reasonable when compared with the 11.7 per cent for forage yield of perennial ryegrass (Hill \& Samuel, 1971), which is expected to be less variable than seed yield. Forage yield ranging from 22 to 65 per 
cent was also reported in perennial ryegrass by Troughton (1970).

\section{Causal modelling}

The different methods used in this paper to investigate relations between interaction and environmental factors all identified the same variables as important. Despite the low number of independent measurements for the explanatory variables, which must have induced low power for most of the regression-related methods, this agreement of methods guarantees that the selected variables were at least statistically related to the interaction. For further insight into causal relations, developmental processes should be monitored through time, and not be characterized solely by an end product such as seed yield. This necessitates the use of statistical models that can accommodate changing relationships between numbers of variables through time, such as linear structural relationships models (Bollen, 1989). An alternative might be the use of simulation models for crop growth and development to bridge the gap between physiological studies and plant breeding practice (Hammer \& Vanderlip, 1989).

\section{Acknowledgements}

We want to thank L. C. P. Keizer for his help with the figures, and J. B. Denis, C. Hackett, H. Jansen, A. P. M. den Nijs and P. Stam for comments on earlier versions of the paper.

\section{References}

ABOU-EL-FITTOUH, H. A., RAWLINGS, J. O. AND MILLER, P. A. 1969. Genotype by environment interactions in cotton - their nature and related environmental variables. Crop. Sci., 9, $377-381$.

ATKInSON, A. C. 1985. Plots Transformations, and Regression. Clarendon Press, Oxford.

BARKER, R. E., HOVIN, W. A., CARLSON, I. T., DROLSOM, P. N., SLEPER, D. A. AND ROSS, J. G. 1981. Genotype-environment interactions for forage yield of reed canarygrass clones. Crop. Sci., 21, 567-571.

Bollen, K. A. 1989. Structural Equations Modelling with Latent Variables. Wiley, New York.

BREESE, E. L. 1969. The measurement and significance of genotype-environment interactions in grasses. Heredity, 24, 27-44.

DENIS, J. B. 1980. Analyse de regression factorielle. Biom. Praxim., 20, 1-34.

DENIS, J. B. 1988. Two way analysis using covariates. Statistics, 19, 123-132.

Elgersma, A. 1990a. Genetic variation for seed yield in perennial ryegrass (Lolium perenne L.). Plant Breeding, 105, 117-125.
Elgersma, A. 1990b. Seed yield related to crop development and to yield components in nine cultivars of perennial ryegrass (Lolium perenne L.). Euphytica, 49, 141-154.

FINLAY, K. W. AND WILKINSON, G. N. 1963. The analysis of adaptation in a plant-breeding programme. Aust. J. Agric. Res., 14, 742-754.

FREEMAN, G. H. AND DOWKER, B. D. 1973. The analysis of variation between and within genotypes and environments. Heredity, 30, 97-109.

FRIPP, Y. J. 1972. Genotype-environmental interactions in Schizophyllum commune. II Assessing the environment. Heredity, 28, 223-238.

GABRIEL, K. R. 1978. Least squares approximation of matrices by additive and multiplicative models. J. R. Stat. Soc. Ser. $B, 40,186-196$.

GAUCH, H. G. Jr 1988. Model selection and validation for yield trials with interaction. Biometrics, 44, 705-715.

GOLLOB, H. F. 1968. A statistical model which contains features of factor analytic and analysis of variance techniques. Psychometrika, 33, 73-115.

GOODMAN, L. A. AND HABERMAN, S. J. 1990. The analysis of nonadditivity in two-way analysis of variance. J. Am. Stat. Ass., 85, 139-145.

GORMAN, D. P., KANG, M. S. AND MILAM, M. R. 1989. Contribution of weather variables to genotype $\times$ environment interaction in grain sorghum. Plant Breeding, 103, 299-303.

GRAY, E. 1982. Genotype $\times$ environment interactions and stability analysis for forage yield of orchardgrass clones. Crop. Sci., 22, 19-23.

HAMMER, G. L. AND VANDERLIP, R. L. 1989. Genotype-byenvironment interaction in grain sorghum. III. Modeling the impact in field environments. Crop. Sci., 29, 385-391.

HAMPTON, J. G. AND HEBBLETHWAITE, P. D. 1983. The effects of the environment at anthesis on the seed yield and yield components of perennial ryegrass (Lolium perenne $\mathbf{L}$.) $\mathrm{cv}$. S.24. J. Applied Seed Prod., 1, 21-22.

HARDWICK, R. C. AND WOOD, J. T. 1972. Regression methods for studying genotype-environment interactions. Heredity, 28, 209-222.

HILL, J. AND SAMUEL, C. J. A. 1971. Measurement and inheritance of environmental response amongst selected material of Lolium perenne. Heredity, 27, 265-276.

KANG, M. S. AND GORMAN, D. P. 1989. Genotype $\times$ environment interaction in maize. Agron. J., 81, 662-664.

KEMPTON, R. A. 1984. The use of biplots in interpreting variety by environment interactions. J. Agric. Sci., Camb., 103, 123-135.

KNIGHT, R. 1970. The measurement and interpretation of genotype-environment interactions. Euphytica, 19, 225235.

MANDEL, J. 1961. Non-additivity in two-way analysis of variance. J. Am. Stat. Ass., 56, 878-888.

NGUYEN, H. T., SLEPER, D. A. AND HUNT, K. L. 1980. Genotype $\times$ environment interactions and stability for herbage yield of tall fescue synthetics. Crop. Sci., 20, 221-224.

PERKINS, J. M. 1972. The principal components analysis of genotype-environmental interactions and physical measures of the environment. Heredity, 29, 51-70.

SAEED, M. AND FRANCIS, C. A. 1984. Association of weather 
variables with genotype $\times$ environment interactions in grain sorghum. Crop. Sci., 24, 13-16.

SAMUEL, C. J. A., HILl, J., BREESE, E. L. AND HUNT. K. L. 1970. Assessing and predicting environmental response in Lolium perenne. J. Agric. Sci., Camb., 75, 1-9.

SNEDECOR, G. W. AND COCHRAN, w. G. 1980. Statistical Methods, 7 th edn. Iowa State University Press, Ames.

STEFANSKY, w. 1972. Rejecting outliers in factorial designs. Technometrics, 14, 469-479.

TAN, W. K., TAN, G. Y. AND WALTON, P. D. 1979. Regression analysis of genotype-environment interaction in smooth bromegrass. Crop. Sci., 19, 393-396.
TROUGHTON, A. 1970. Intra-varietal variation of yield in two varieties of Lolium perenne L. Euphytica, 19, 382-389.

WESTCOTT, B. 1986. Some methods of analysing genotype-environment interaction. Heredity, 56, 243-253.

wooD, J. T. 1976. The use of environmental variables in the interpretation of genotype-environment interaction. Heredity, 37, 1-7.

YATES, F. AND COCHRAN, w. G. 1988. The analysis of groups of experiments. J. Agric. Sci., Camb., 28, 556-580.

zOBEL, R. W., WRIGHT, M. J. AND GAUCH, H. G. 1988. Statistical analysis of a yield trial. Agron. J., 80, 388-393. 